Check for updates

Cite this: Chem. Commun., 2020,

56, 11106

Received 16th June 2020,

Accepted 5th August 2020

DOI: $10.1039 / \mathrm{d} 0 \mathrm{cc} 04174 \mathrm{~b}$

rsc.li/chemcomm

\section{Hydrogen evolution reaction mediated by an all-sulfur trinuclear nickel complex $\dagger$}

\author{
Cyril Pieri, ${ }^{a}$ Anirban Bhattacharjee, ${ }^{b}$ Alexandre Barrozo, (D) a Bruno Faure, (D) a \\ Michel Giorgi, (D) c Jennifer Fize, ${ }^{c}$ Marius Réglier, ${ }^{a}$ Martin Field, *d Maylis Orio, (DD *a \\ Vincent Artero iD d and Renaud Hardré ${ }^{a}$
}

We report the synthesis and the characterization of a trinuclear nickel complex. Solid state and solution studies using $X$-ray diffraction, NMR and UV-vis spectroscopy highlight the square planar geometries around the metal centers and an all-sulfur coordination sphere. It exhibits significant electrocatalytic activity for hydrogen evolution in DMF using $\mathrm{Et}_{3} \mathrm{NHCl}$ as the proton source. DFT studies suggest that sulfur atoms act as proton relay, as proposed in [NiFe] hydrogenases.

The limited sources of fossil fuels, together with their environmental impact, render them unviable in the long run. This is aggravated by an increasing energy demand worldwide, resulting in higher prices, as well as with the lack of renewability of fossil energy at the human time scale. ${ }^{1}$ To the contrary, dihydrogen seems to be an ideal substitute, since it is based on the most abundant atom in the universe, and its combustion yields high energy, with water as the only waste. ${ }^{2}$ The main issue remains with its production. While water electrolysis appears as the most efficient way to produce hydrogen, the flexible proton exchange membrane technology requires the use of platinum, a rare and expensive metal with limited stocks. ${ }^{3}$ In the search for an economically competitive way of producing dihydrogen with non-noble metal-based catalysts, Nature can guide us and inspiration can be found with the $[\mathrm{NiFe}]$ hydrogenases. This family of enzymes is a very attractive example as it is the most abundant hydrogenases among living organisms. Their active sites are composed of two metal ions, iron and nickel, the latter lying in a rare all-sulfur and distorted tetrahedral coordination geometry. ${ }^{4-6}$ Many bio-inspired complexes

\footnotetext{
${ }^{a}$ Aix Marseille Univ, CNRS, Centrale Marseille, iSm2, Marseille, France.

E-mail: renaud.hadre@univ-amu.fr, maylis.orio@univ-amu.fr

${ }^{b}$ Socivolta Inc., 3 Place Ville Marie, suite 400, Montreal, QC H3B 2E3, Canada

${ }^{c}$ Aix Marseille Univ, CNRS, Centrale Marseille, Spectropole FR1739, Marseille, France

${ }^{d}$ Univ. Grenoble Alpes, CNRS, CEA, IRIG, Laboratoire de Chimie et Biologie des Métaux, 17 rue des Martyrs, 38000 Grenoble, France. E-mail: martin.field@cea.fr $\dagger$ Electronic supplementary information (ESI) available. CCDC 939713. For ESI and crystallographic data in CIF or other electronic format see DOI: 10.1039/ d0cc04174b
}

mimicking this active site can be found in literature ${ }^{7-14}$ These models generally show some degree of variation from the enzyme active site: metals, coordinating atoms, bridging and exogenous ligands, e.g. $\mathrm{CO}$ and $\mathrm{CN}^{-}{ }^{15}$ To reproduce the features of the [NiFe] hydrogenase active site, an all-sulfur nickel complex was obtained by Yamamura et al. in 1985, long before the crystal structure of the enzyme was resolved. ${ }^{16}$ Sellman et al. also explored a certain number of all-sulfur nickel complexes. ${ }^{17}$ Once the structure of the [NiFe] hydrogenase was known, many heterobimetallic complexes were then developed. ${ }^{18}$ Unlike the enzyme, all of these complexes suffered from a lack of nickel centred reactivity ${ }^{6}$ and the situation only changed recently. ${ }^{11,19-23}$ Moreover, the hydrogen producing catalytic performances of these complexes with respect to overpotential requirement and turnover frequency (TOF) towards hydrogen production were far below those of [NiFe] hydrogenases, operating at the thermodynamic equilibrium with a TOF around $1000 \mathrm{~s}^{-1} \cdot{ }^{24,25}$ The high activity of hydrogenase depends on the presence of proton relays at the vicinity of the active site. In [NiFe] hydrogenases, terminal cysteinates have been assigned this role. ${ }^{6}$ While there are several examples of $\mathrm{FeFe}$ hydrogenase models with terminal thiolate ligands prone to protonation, ${ }^{26,27}$ there is only one known example of a NiFe complex, and this was only observed under strongly acidic conditions, not pertinent for catalysis. ${ }^{28}$ In this context, we have developed a bio-inspired nickel complex bearing an all-sulfur and constrained ligand that resembles the Ni-center of the enzyme active site with its cysteine-thiolate ligands implicated as bases in proton transfer reactions.

Inspired by the seminal work of Bosnich and Pickett, ${ }^{29-31}$ our strategy to prepare the trithiol 3 was to start the synthesis from the thiol 1 easily accessible according to the Bosnich procedure. $^{29,32}$ Compound 2 was then obtained by $S$-alkylation of 1 with 2-bromoethyl-trityl-sulfide. Removal of the trityl substituent in dry acidic condition $\left(\mathrm{CF}_{3} \mathrm{COOH}\right)$ and the reduction of the disulfide moiety by triethyltin hydride led to the trithiol 3. This overall process provided access to the trithiol 3 which was used for the synthesis of Ni(II) complexes. Thus, the reaction of the ligand 3 with 1 eq. of $\left[\mathrm{Ni}\left(\mathrm{CH}_{3} \mathrm{CN}\right)_{6}\right]\left(\mathrm{BF}_{4}\right)_{2}$ in 


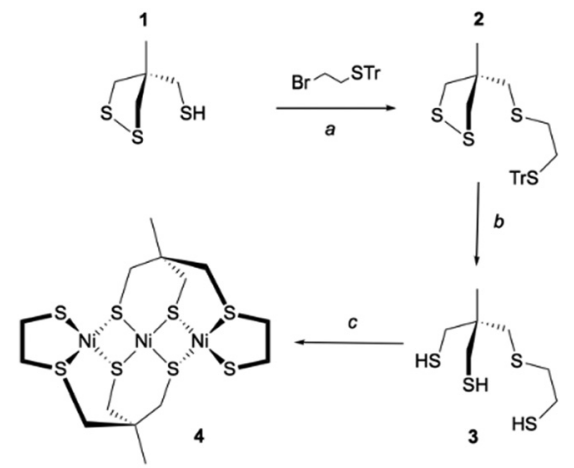

Scheme 1 Synthetic route for the nickel complex 4. Conditions: (a) $\mathrm{NaH}$, $\mathrm{THF}, 0{ }^{\circ} \mathrm{C}$ to RT, overnight, $66 \%$; (b) $\mathrm{CF}_{3} \mathrm{COOH}$ (excess), $\mathrm{Et} 33 \mathrm{SiH}$ (3 eq.), $\mathrm{CH}_{2} \mathrm{Cl}_{2}$, RT overnight, 81\%; (c) [Ni( $\left.\left.\mathrm{CH}_{3} \mathrm{CN}\right)_{6}\right]\left(\mathrm{BF}_{4}\right)_{2}, \mathrm{~K}_{2} \mathrm{CO}_{3}$ (3 eq.), $\mathrm{CH}_{3} \mathrm{CN}, \mathrm{RT}, 2 \mathrm{~h}$.

acetonitrile with $\mathrm{K}_{2} \mathrm{CO}_{3}$ as base led to the formation of a soluble complex that rapidly evolved by the formation of a brown precipitate. Filtration followed by liquid chromatography with $\mathrm{CH}_{2} \mathrm{Cl}_{2}$ as eluant allowed us to get the pure $\mathrm{Ni}(\mathrm{II})$ complex 4 in $45 \%$ yield (Scheme 1 ).

Suitable crystals were obtained from a saturated solution of the complex in $\mathrm{CH}_{3} \mathrm{CN}$. The complex crystallizes as a symmetric trimer with the central Ni-atom lying on the crystallographic two-fold axis (Fig. 1).

The asymmetric unit is thus composed of half the complex. The coordination geometries of the metals are square planar with small deviations from planar (defined by the $\mathrm{Ni}$ and the four coordinated S atoms, Fig. S6 and Table S1, ESI + ): the maximum out-of-plane distances are close to $0.15 \AA$ and $0.19 \AA$ (S1 in plane P1 including Ni2 and S1 in plane P2 including Ni1, respectively). The dihedral angle between $\mathrm{P} 1$ and $\mathrm{P} 2$ is equal to $73.0697(4)^{\circ}$, while the dihedral angle between P1 and the symmetric plane $\mathrm{P} 1^{\prime}$ (symmetry code: $1-x, y, 3 / 2-z$ ) is equal to $33.8471(8)$. The structure of compound $\mathbf{4}$ is therefore very compact and folded with a bowl shape and a small accessible cavity toward the central Ni-atom (mean width and depth equal to $3.4 \AA$ and $4.9 \AA$, respectively, Table S2, ESI $\dagger$ ).

To check that the structure of 4 corresponds to the one found in solution, we performed the UV-vis titration of the ligand 3 by nickel perchlorate in the presence of triethylamine in DMF. Upon
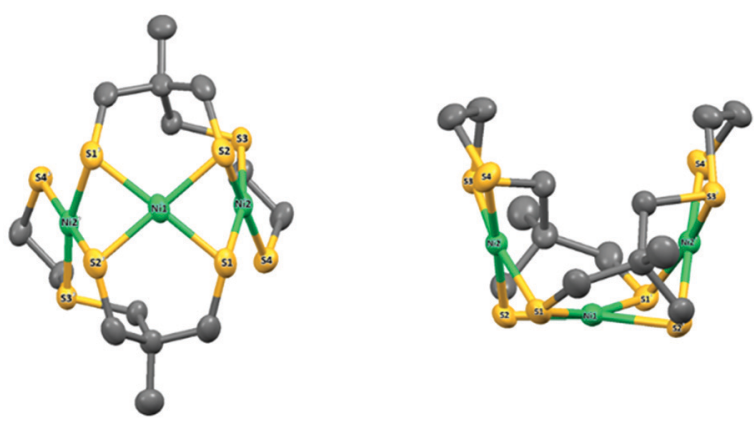

Fig. 1 X-ray molecular structure of 4 with atom labelling scheme and ellipsoid parameters at 50\% probability level. Hydrogen atoms and carbon labels are omitted for clarity. addition of $\left[\mathrm{Ni}\left(\mathrm{H}_{2} \mathrm{O}\right)_{6}\right]\left(\mathrm{ClO}_{4}\right)$, the UV-vis spectrum displays three absorption bands at $290 \mathrm{~nm}, 410 \mathrm{~nm}$ and $540 \mathrm{~nm}$ (Fig. S3, ESI †).

Plotting the molecular extinction coefficient as a function of the number of $\mathrm{Ni}(\mathrm{II})$ equivalents for each absorption band allowed us to determine the stoichiometry of the complex (Fig. S4, ESI $\dagger$ ). Analysis of the titration curves for both the 410 and $540 \mathrm{~nm}$ bands support the formation of a trinuclear species like 4 with a $2: 3$ nickel to ligand ratio, e.g. 2 ligands for 3 metal ions.

To support the above assignment, we used time-dependent DFT to calculate the theoretical UV-vis spectrum of 4 (Fig. S9 and Table $\mathrm{S} 5, \mathrm{ESI} \dagger)$ in the trimer form revealed by X-ray diffraction. Our computations support that its UV-vis spectrum is dominated by three main absorption bands of different intensity (Fig. S10, ESI $\dagger$ ). The low-energy absorption is assigned to a $\mathrm{d}-\mathrm{d}$ transition while the two other spectral features are attributed to charge transfers from the ligand to metal (Fig. S11 and Table S4, ESI $\dagger$ ). Both the shape and relative intensities of the calculated spectrum are in pretty fair agreement with the spectrum measured in solution.

The electrochemical study of $\mathbf{4}$ was performed by cyclic voltammetry between +0.5 and $-2.5 \mathrm{~V} v s$. $\mathrm{Fc}^{+/ 0}$ (Fig. 2). In the cathodic region, two one-electron redox systems were observed: one quasi-reversible at $-1.65 \mathrm{~V}\left(1 / 2\left(E_{\mathrm{pc}^{*}}{ }^{*} E_{\mathrm{pa}^{*}}\right)\right)$ and another irreversible at $-2.09 \mathrm{~V} v s$. $\mathrm{Fc}^{+/ 0}\left(E_{\mathrm{pc}}{ }^{* *}\right)$. The plot of the peak current versus the square root of the scan rates for the reversible cathodic wave was found to be linear, indicating that it is a diffusion-controlled process (Fig. S7, ESI $\dagger$ ). In the anodic direction, the $\mathrm{CV}$ revealed one oxidative process with an irreversible wave observed at $+0.22 \mathrm{~V} v s$. $\mathrm{Fc}^{+/ 0}$.

In an effort to gain insight into the nature of the species observed during cyclic voltammetry experiments, we calculated the structures of the putative species resulting from one and twoelectron reduction of 4 (Fig. S12-S14 and Tables S6-S8, ESI †), and their electronic properties. Upon reduction, our results indicate that most of the spin density is distributed at one nickel center (Fig. S15, ESI $\dagger$ ). The first reduction process of 4 occurs at the central metal site leading to the formation of a Ni(II)-Ni(I)-Ni(II) complex. The two-electron reduction of 4 results in a triplet ground spin state $S=1$ with a stabilization energy of $24 \mathrm{~kJ} \mathrm{~mol}^{-1}$ over the singlet state $S=0$. This result supports a metal-based reduction occurring on another nickel center (Fig. S16, ESI $\dagger$ ) and leading to the formation of a $\mathrm{Ni}(\mathrm{I})-\mathrm{Ni}(\mathrm{II})-\mathrm{Ni}(\mathrm{I})$ complex. We can

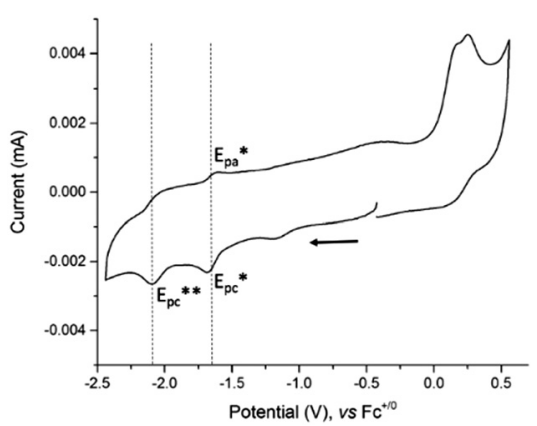

Fig. 2 Cyclic voltammogram of $\mathbf{4}$, concentration $0.3 \mathrm{mM}$ at a stationary glassy carbon electrode ( $3 \mathrm{~mm}$ diameter) in $\mathrm{DMF}+0.1 \mathrm{M} \mathrm{NEt}_{4} \mathrm{ClO}_{4}$. Scan rate $100 \mathrm{mV} \mathrm{s}^{-1}$ 
notice a subsequent electronic rearrangement between the first and second reduction, which explains the irreversibility observed experimentally for the second redox system.

Redox potential calculations were conducted to fully assign the electrochemical events (Table S3, ESI $\dagger$ ). The computed values for the one- and two-electron reduction processes are in good agreement with experiment which indicates that the two cathodic systems correspond to a monoelectronic processes and support the above assignments of the reduction loci in 4 .

To examine the capability of complex 4 to mediate proton reduction catalysis, its electrochemical behaviour was studied by cyclic voltammetry in the presence of $\mathrm{Et}_{3} \mathrm{NHCl}\left(\mathrm{p} K_{\mathrm{a}}=9.2 \mathrm{in}\right.$ $\mathrm{DMF})^{33,34}$ as proton source.

Cyclic voltammograms of $\mathbf{4}$ were recorded under argon in DMF solutions with increased amounts of $\mathrm{Et}_{3} \mathrm{NHCl}$ (Fig. 3) and show a large irreversible catalytic wave with a mid-wave potential $E_{\text {cat }}^{0}$ of $-1.70 \pm 0.03 \mathrm{~V}$ vs. $\mathrm{Fc}^{+/ 0}$, i.e. close to the reduction potential of 4 . The current response of this peakshaped wave is directly proportional to the concentration of protons in the electrolyte solution (Fig. S8, ESI $\dagger$ ). A value of $590 \mathrm{mV}$ was calculated for the overpotential requirement of 4 for proton reduction in the presence of $\mathrm{Et}_{3} \mathrm{NHCl}$ in $\mathrm{DMF}{ }^{34}$

To confirm that the observed catalytic waves correspond to the electrocatalytic reduction of protons into hydrogen, we performed a bulk electrolysis experiment of a DMF solution of $\mathrm{Et}_{3} \mathrm{NHCl}$ in excess $(200 \mathrm{mM})$ and $4(1 \mathrm{mM})$. Gas products were monitored by continuous in-line GC analysis. A potential of $-1.60 \mathrm{~V}$ versus $\mathrm{Fc}^{+/ 0}$ was applied to the mercury-pool working electrode resulting in the immediate formation of hydrogen. This experiment rules out the possibility that proton reduction occurs as the result of deposition of nickel nanoparticles on the electrode surface since they would amalgamate within the mercury pool electrode. Consequently, under these conditions catalysis mediated by $\mathbf{4}$ is expected to be homogeneous in nature. During the $15 \mathrm{~h}$ experiment, a turnover number of 5 was achieved with a moderate faradaic yield of $30 \%$; indicating some degradation of the complex during turn-over.

DFT calculations were finally conducted to decipher the reaction mechanism of hydrogen evolution by 4 (Scheme 2). We

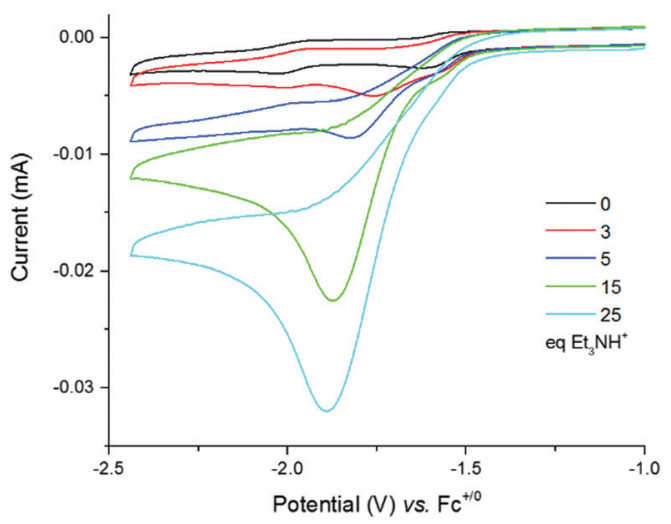

Fig. 3 Cyclic voltammograms of a $0.25 \mathrm{mM}$ solution of 4 in DMF $(0.1 \mathrm{M}$ $\mathrm{NEt}_{4} \mathrm{ClO}_{4}$ ) with increasing amounts of $\mathrm{Et}_{3} \mathrm{NHCl}(0-55$ equiv.) recorded at a glassy carbon electrode ( $3 \mathrm{~mm}$ diameter) and $100 \mathrm{mV} \mathrm{s}^{-1}$.

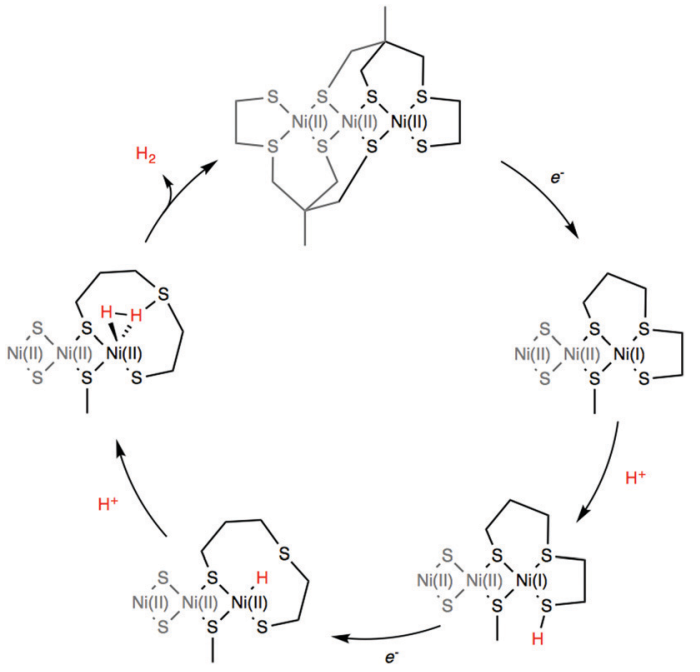

Scheme 2 Proposed DFT computed reaction mechanism for hydrogen evolution mediated by 4.

propose the catalytic cycle for $\mathrm{H}_{2}$ evolution presented in Scheme 2 and based on the ECEC sequence, classically found for cobalt and nickel complexes. ${ }^{35-37} \mathrm{UV} /$ vis measurements performed in the absence and presence of $\mathrm{Et}_{3} \mathrm{NHCl}$ (Fig. S5, ESI $\dagger$ ) display almost identical features, indicating that the structure of 4 is unaffected by the addition of a proton source of such strength. From the cyclic voltammetry measurements in the presence of acid, it can be inferred that the reaction proceeds from the oneelectron reduced species with a midwave electrocatalytic potential equal to that of the first reduction in 4 denoted $\left[\mathrm{Ni}_{3}{ }^{\prime} \mathrm{S}_{4}{ }_{2}\right]$. The first reduction at the Ni site was calculated at potentials of -1.84 and $-2.02 \mathrm{~V}$ vs. $\mathrm{Fc}^{+/ 0}$ when using the B86 and B3LYP functionals, respectively (Table $\mathrm{S} 3, \mathrm{ESI} \dagger$ ). We then investigated the protonation of the reduced complex $\left[\mathrm{Ni}_{3}^{\prime} \mathrm{S}^{\prime}{ }_{2}\right]^{-}$with $\mathrm{Et}_{3} \mathrm{NH}^{+}$yielding $\left[\mathrm{HNi}_{3}{ }^{\prime} \mathrm{S}^{\prime}{ }_{2}\right]$. Two distinct protonation sites could be found. The most stable isomer (by 28 and $61 \mathrm{~kJ} \mathrm{~mol}^{-1}$ with BP86/B3LYP, respectively) is protonated on a terminal thiolate ligand coordinated on a peripheral $\mathrm{Ni}$ ion that remains in a square-planar environment (Fig. S17 and Table S9, ESI $\dagger$ ). This reaction is calculated to be almost isergonic. Another isomer, with higher energy, is obtained when protonation occurs at the Ni site thus yielding a hydride derivative with a distorted square-based pyramidal geometry (Fig. S18 and Table S10, ESI $\dagger$ ). Reduction of the two isomers of $\left[\mathrm{HNi}_{3}{ }^{\prime} \mathrm{S}_{4}{ }_{2}\right]$ yielding $\left[\mathrm{HNi}_{3}{ }^{\prime} \mathrm{S}_{4}{ }_{2}\right]^{-}$is calculated to occur at potentials close to the one calculated for the first reduction of $\left[\mathrm{Ni}_{3}{ }^{\prime} \mathrm{S}_{4}{ }_{2}\right]$. We note that the stability order of the two isomers is inverted after this reduction step: in that case the sulfur-protonated species (Fig. S19 and Table S11, ESI $\dagger$ ) is less stable (by 76 and $24 \mathrm{~kJ} \mathrm{~mol}^{-1}$ with BP86/B3LY, respectively) than the Ni-hydride square-planar isomer (Fig. S20 and Table S12, ESI $\dagger$ ) in which one thioether ligand has been eliminated from the $\mathrm{Ni}$ coordination sphere and replaced by the hydride ligand.

Finally, protonation of the reduced hydride species $\left[\mathrm{HNi}_{3}{ }^{\prime} \mathrm{S}^{\prime}{ }_{2}\right]^{-}$leads to formation of a dihydrogen complex $\left[\left(\mathrm{H}_{2}\right) \mathrm{Ni}_{3}{ }^{\prime} \mathrm{S}_{4}^{\prime}{ }_{2}\right]$ (Fig. S21 and Table S13, ESI $\dagger$ ). This reaction is calculated to be thermodynamically favorable. The structure is 


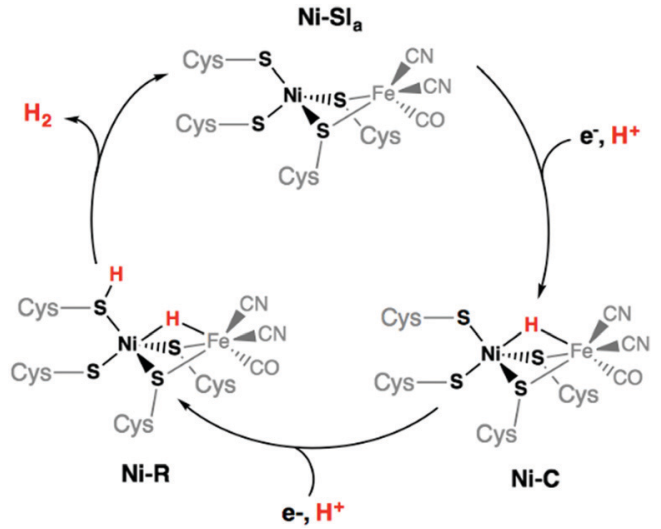

Scheme 3 Catalytic cycle of the [NiFe] hydrogenases involving the Ni-Sla, $\mathrm{Ni}-\mathrm{R}$, and $\mathrm{Ni}-\mathrm{C}$ states

reminiscent of a dihydrogen bond between nickel and sulfur that has been proposed as a key intermediate in the route to $\mathrm{H}_{2}$ evolution at the active site of [NiFe] hydrogenases ( $\mathrm{Ni}-\mathrm{R}$ in Scheme 3). ${ }^{38,39}$ From this dihydrogen complex, liberation of $\mathrm{H}_{2}$ is strongly and entropically favored. Removal of $\mathrm{H}_{2}$ leads to the original structure of $\left[\mathrm{Ni}_{3}{ }^{\prime} \mathrm{S4}_{2}{ }_{2}\right]$ thus closing the catalytic cycle.

In this work, we have reported the experimental and theoretical study of an original trinuclear nickel complex that displays an all-sulfur coordination sphere and exhibits a significant catalytic activity with a moderate overpotential requirement for hydrogen production in DMF using $\mathrm{Et}_{3} \mathrm{NHCl}$ as the proton source. Detailed analysis of the electrocatalytic data combined with DFT calculations allowed us to propose an ECEC catalytic pathway involving Ni-bound terminal thiolate ligand as proton relay mimicking the role of terminal cysteinate ligand in the active site of $[\mathrm{NiFe}]$ hydrogenases.

Further work is currently in progress in our group to develop new bio-inspired mimics of the [NiFe] hydrogenase and to design original polynuclear metal complexes with thiolate ligands capable of mediating efficient hydrogen evolution.

The authors gratefully acknowledge research support of this work by the French National Research Agency (CODEC, ANR-19-CE05_0030_01; $\mathrm{CatH}_{2}$, ANR-07-BLAN-0298; NiFe-Cat, ANR-2010-BLAN-711-1; NiFemim, ANR-DFG-2016-NLE; Labex ARCANE; Graduate school of Chemistry, Biology and Health of Univ. Grenoble Alpes, CBH-EUR-GS, ANR-17-EURE-0003).

\section{Conflicts of interest}

There are no conflicts to declare.

\section{Notes and references}

1 D. A. King, Science, 2004, 303, 176.

2 P. P. Edwards, V. L. Kuznetsov, W. I. F. David and N. P. Brandon, Energy Policy, 2008, 36, 4356.

3 J. R. McKone, S. C. Marinescu, B. S. Brunschwig, J. R. Winkler and H. B. Gray, Chem. Sci., 2014, 5, 865.

4 A. Volbeda, M.-H. Charon, C. Piras, E. C. Hatchikian, M. Frey and J.-C. Fontecilla-Camps, Nature, 1995, 373, 580.
5 A. Volbeda, A. E. Garcin, C. Piras, A. L. de Lacey, V. M. Fernandez, E. C. Hatchikian, M. Frey and J.-C. Fontecilla-Camps, J. Am. Chem. Soc., 1996, 118, 12989.

6 W. Lubitz, H. Ogata, O. Rüdiger and E. Reijerse, Chem. Rev., 2014, 114, 4081.

7 D. Sirbu, T. Straistari and A. C. Benniston, Hydrogenases: From Biomimetic to Bioinspired Models, Bioinspired Chemistry, From Enzymes to Synthetic Models, 2019, vol. 5, p. 89.

8 T. B. Rauchfuss, Acc. Chem. Res., 2015, 48, 2107.

9 M. Y. Darensbourg, E. J. Lyon and J. J. Smee, Coord. Chem. Rev., 2000, 206, 533.

10 Z. Li, Y. Ohki and K. Tatsumi, J. Am. Chem. Soc., 2005, 127, 8950.

11 D. Brazzolotto, M. Gennari, N. Queyriaux, T. R. Simmons, J. Pecaut, S. Demeshko, F. Meyer, M. Orio, V. Artero and C. Duboc, Nat. Chem., 2016, 8, 1054.

12 S. Canaguier, M. Field, Y. Oudart, J. Pécaut, M. Fontecave and V. Artero, Chem. Commun., 2010, 46, 5876.

13 D. Basu, T. Spencer Bailey, N. Lalaoui, C. P. Richers, T. J. Woods, T. B. Rauchfuss, F. Arrigoni and G. Zampella, Inorg. Chem., 2019, 58(4), 2430.

14 N. Coutard, N. Kaeffer and V. Artero, Chem. Commun., 2016, 52, 13728.

15 T. R. Simmons, G. Berggrena, M. Bacchi, M. Fontecave and V. Artero, Coord. Chem. Rev., 2014, 270-271, 127.

16 T. Yamamura, H. Miyamae, Y. Katayama and Y. Sasaki, Chem. Lett., 1985, 269.

17 D. Sellmann, S. Fünfgelder, G. Pohlmann, F. Knoch and M. Moll, Inorg. Chem., 1990, 29, 4772.

18 S. Kaur-Ghumaan and M. Stein, Dalton Trans., 2014, 43, 9392.

19 H. Tang and M. B. Hall, J. Am. Chem. Soc., 2017, 139, 18065.

20 D. Brazzolotto, L. Wang, H. Tang, M. Gennari, N. Queyriaux, C. Philouze, S. Demeshko, F. Meyer, M. Orio, V. Artero, M. B. Hall and C. Duboc, ACS Catal., 2018, 8, 10658.

21 G. M. Chambers, M. T. Huynh, Y. Li, S. Hammes-Schiffer, T. B. Rauchfuss, E. Reijerse and W. Lubitz, Inorg. Chem., 2016, 55, 419.

22 S. Ding, P. Ghosh, A. M. Lunsford, N. Wang, N. Bhuvanesh, M. B. Hall and M. B. Y. Darensbourg, J. Am. Chem. Soc., 2016, 138, 12920.

23 S. Ding, P. Ghosh, M. Y. Darensbourg and M. B. Hall, Proc. Natl. Acad. Sci. U. S. A., 2017, 114, E9775.

24 M. E. Ahmed and A. Dey, Curr. Opin. Electrochem., 2019, 15, 155.

25 D. Schilter, J. M. Camara, M. T. Huynh, S. Hammes-Schiffer and T. B. Rauchfuss, et al., Chem. Rev., 2016, 116, 8693.

26 U.-P. Apfel, D. Troegel, Y. Halpin, S. Tschierlei, U. Uhlemann, H. Görls, M. Schmitt, J. Popp, P. Dunne, M. Venkatesan, M. Coey, M. Rudolph, J. G. Vos, R. Tacke and W. Weigand, Inorg. Chem., 2010, 49, 10117.

27 R. Zaffaroni, T. B. Rauchfuss, D. L. Gray, L. De Gioia and G. Zampella, J. Am. Chem. Soc., 2012, 134, 19260.

28 K. Weber, T. Krämer, H. S. Shafaat, T. Weyhermüller, E. Bill, M. van Gastel, F. Neese and W. Lubitz, J. Am. Chem. Soc., 2012, 134, 20745.

29 C. Kolomyjec, J. Whelan and B. Bosnich, Inorg. Chem., 1983, 22, 2343.

30 M. Razavet, S. C. Davies, D. L. Hughes and C. J. Pickett, Chem. Commun., 2001, 847.

31 M. Razavet, S. C. Davies, D. L. Hughes, J. E. Barclay, D. J. Evans, S. A. Fairhurst, X. Liu and C. J. Pickett, Dalton Trans., 2003, 586.

32 R. A. Valiulin and A. G. Kutateladze, J. Org. Chem., 2008, 73, 335.

33 K. Izutsu, Acid-Base Dissociation Constants, Dipolar Aprotic Solvents, Blackwell Scientific, Oxford, UK, 1990.

34 V. Fourmond, P. Jacques, M. Fontecave and V. Artero, Inorg. Chem., 2010, 49, 10338.

35 V. Artero and J.-M. Saveant, Energy Environ. Sci., 2014, 7, 3808.

36 N. Kaeffer, M. Chavarot-Kerlidou and V. Artero, Acc. Chem. Res., 2015, 48, 1286.

37 N. Queyriaux, R. T. Jane, J. Massin, V. Artero and M. ChavarotKerlidou, Coord. Chem. Rev., 2015, 304-305, 3.

38 P. E. M. Siegbahn, J. W. Tye and M. B. Hall, Chem. Rev., 2007, $107,4414$.

39 G. Dong and U. Ryde, JBIC, J. Biol. Inorg. Chem., 2016, 21, 383. 